\title{
Systematic review and meta-analysis of evaluation of selective cesarean section in postpartum pelvic floor function recovery under perineal ultrasound
}

\author{
Yu Chen", Xuna Geng", Haixia Zhou, Weijing Wang, Yu Liang, Chunye Zhang, Lufang Wang \\ Ultrasound Department, Shijiazhuang Fourth Hospital, Shijiazhuang, China \\ Contributions: (I) Conception and design: Y Chen, X Geng, L Wang; (II) Administrative support: H Zhou; (III) Provision of study materials or \\ patients: Y Chen, X Geng, W Wang, Y Liang; (IV) Collection and assembly of data: All authors; (V) Data analysis and interpretation: Y Chen, H \\ Zhou, W Wang, Y Liang, L Wang; (VI) Manuscript writing: All authors; (VII) Final approval of manuscript: All authors. \\ \#These authors contributed equally to this work. \\ Correspondence to: Lufang Wang. Ultrasound Department, Shijiazhuang Fourth Hospital, 16 Tan Gubei Street, Shijiazhuang, China. \\ Email: wanglufang2021@163.com.
}

Backgrounda Different delivery modes can affect the early pelvic floor function of puerpera, but there are no reports on the systematic evaluation of the effects of selective cesarean section delivery (CSD) and vaginal delivery (VD) on the pelvic floor function of puerpera.

Methods: We searched for clinical controlled studies on the evaluation of pelvic floor function and performance after CSD and VD, published between 1 January 2010 and 1 August 2021, in the databases of PubMed, Embase, The Cochrane Library, and Web of Science. Literature was screened according to the inclusion and exclusion criteria. The quality of trials included in the studies was evaluated using the Cochrane Working Manual (5.3). Meta-analysis of the extracted data from the eligible articles was performed using Review Manager 5.3 software. The heterogeneity was assessed by chi-square, and $\mathrm{P}<0.05$ was considered statistically significant among groups.

Results: A total of 3,704 parturient women were included in 10 articles, including 1,072 cases in the CSD group and 2,632 cases in the VD group. Meta-analysis showed that pelvic floor muscle strength \{mean difference (MD) [95\% confidence interval (CI)]: -12.51 ( -17.10 to -7.91$) ; Z=5.34 ; \mathrm{P}<0.00001\}$ and bladder neck strength decreases in the CSD group [standardized mean difference (SMD) (95\% CI): 1.01 (0.73 to 1.29); $Z=7.08 ; P<0.00001]$ were higher than those in the VD group. In addition, the maximum urine flow [MD (95\% CI): -6.86 (-9.32 to -4.39$) ; Z=5.46 ; \mathrm{P}<0.00001]$, bladder angle [MD (95\% CI): -3.82 ( -4.54 to -3.11$)$; $\mathrm{Z}=10.46 ; \mathrm{P}<0.00001$ ], stress urinary incontinence (SUI) rate [relative risk (RR) (95\% CI): 0.56 (0.35 to 0.88$)$; $\mathrm{Z}=2.52 ; \mathrm{P}=0.01$ ], and pelvic floor organ prolapse rate [odds ratio (OR) (95\% CI): 0.29 (0.09 to 0.89); $\mathrm{Z}=2.17$; $\mathrm{P}=0.03]$ were lower than VD group, and the differences were significant $(\mathrm{P}<0.05)$.

Conclusions: Selective CSD can reduce the injury of pelvic floor muscle during delivery to a certain extent, and reduce the incidence of SUI and pelvic floor organ prolapse in early puerpera; however, such impacts cannot be completely avoided.

Keywords: Selective cesarean section; vaginal delivery (VD); pelvic floor function; meta-analysis

Submitted Dec 19, 2021. Accepted for publication Feb 11, 2022.

doi: 10.21037/apm-22-46

View this article at: https://dx.doi.org/10.21037/apm-22-46 


\section{Introduction}

The female pelvic floor is mainly composed of closed pelvic outlet muscles, fascia, ligaments, and nerves. The levator ani muscle group is the most important supporting structure in the pelvic floor, which plays an important role in childbirth, defecation, and pelvic floor organ support (1). Some studies have suggested that pregnancy and childbirth are important influencing factors of levator ani injury (2). In order to ensure the perfection and integrity of the anatomical structure of the pelvic floor during childbirth, the pelvic floor tissue will maintain physiological needs through a series of changes, which may easily lead to changes in the anatomical structure of the female pelvic floor after childbirth. If there is no effective treatment and rest, pelvic floor dysfunction may occur. Female pelvic floor dysfunction seriously affects the quality of life of female patients, and the mechanism of the disease is related to the levator ani muscle injury caused by childbirth. close relationship (3). In the process of childbirth, natural childbirth causes much more damage to the pelvic floor than cesarean section. When the degree of damage exceeds the limit of its own repair, the function of pelvic floor remodeling will be decompensated, which will lead to abnormal changes in the anatomical structure of the female pelvic floor and pelvic floor dysfunction. Female pelvic floor dysfunction is a group of clinical syndromes mainly caused by abnormal defects, degeneration, damage, and dysfunction of the support system of the pelvic floor. Female pelvic floor dysfunction mainly includes pelvic organ prolapse, stress urinary incontinence (SUI), sexual dysfunction, fecal incontinence, and chronic pelvic pain (4). A large number of clinical epidemiological studies have shown that age, obesity, genetics, pregnancy, childbirth, pelvic surgery, and chronic cough are all risk factors for pelvic floor dysfunction in women. Pregnancy and childbirth are independent risk factors for female pelvic floor dysfunction and play an important role in the occurrence of SUI (5). The relaxation or rupture of the pelvic floor supporting tissue is the main pathogenesis of pelvic floor dysfunction, and the levator ani muscle is the most important part of this supporting tissue. Several studies have found that $30-40 \%$ of women with pelvic floor organ prolapse have partial or complete avulsion of the levator ani muscle.

Clinical assessment of pelvic floor muscle function is mainly carried out by Oxford muscle strength grading and vaginal electromyography (EMG) (6). However, Oxford muscle strength grading is greatly influenced by subjective factors and has the disadvantage of poor repeatability, so the clinical diagnosis rate is low (7). Vaginal EMG can objectively reflect the state of the pelvic floor muscles, but the results are influenced by the client's motor coordination (8). Ultrasound imaging can observe the morphology and structure of levator ani muscle, and has the advantages of safety, reliability, non-invasiveness, and is economical, so it is widely used in the evaluation of pelvic floor function. Rørtveit et al. [2014] (9) conducted a statistical analysis on the occurrence of urinary incontinence and pelvic organ prolapse in different time periods of cesarean section and vaginal delivery (VD). It was found that women who delivered by cesarean section had lower rates of urinary incontinence and pelvic organ prolapse than women who delivered vaginally. Based on the advantages of ultrasound imaging in the evaluation of pelvic floor muscle function, this work focused on the incidence of urinary incontinence and pelvic organ prolapse in cesarean section and VD women on the basis of perineal ultrasound examination. In addition, the morphological and structural change-related indicators were analyzed.

To evaluate the effect of delivery mode on the pelvic floor function of primiparas, this study systematically evaluated the effect of selective cesarean section delivery (CSD) and VD based on ultrasound evaluation of perineal basin on the pelvic floor function of primiparas using metaanalysis. We aimed to provide medical evidence for the early pelvic floor function recovery training of parturient women in the clinical setting. We present the following article in accordance with the MOOSE reporting checklist (available at https://apm.amegroups.com/article/view/10.21037/apm$22-46 / \mathrm{rc})$.

\section{Methods}

\section{Data inclusion}

Parturients based on perineal ultrasound assessment were selected as study subjects. Pelvic floor function assessment methods mainly included: pelvic floor muscle strength measurement, vaginal dynamic pressure, pelvic organ prolapse quantitative indexing method, pelvic floor dysfunction questionnaire, sexual life satisfaction scale, and urinary incontinence quality of life questionnaire. Observation indicators of the included data included information such as study author, year, and country. 


\section{Inclusion and exclusion criteria}

The inclusion criteria were as follows: (I) clinical cohort studies, or case-control studies of selective CSD and VD; (II) participants were parturients of 1 or more pregnancies; (III) the experimental group was selective CSD, and the control group was natural VD; (IV) the outcome measures included pelvic floor muscle strength, maximum urine flow, incidence of SUI, incidence of pelvic floor organ prolapse, and decline of posterior horn and neck of the bladder.

The exclusion criteria were as follows: (I) individual case reports, literature review, and prospective non-randomized controlled trials; (II) research with pelvic floor muscle strength test that did not conform to the International Oxford score, or with the incidence of posterior bladder angle, bladder neck descent, SUI, and pelvic floor organ prolapse by perineal ultrasound; (III) no original data was provided; (IV) duplicate publication of literature.

\section{Retrieval strategy}

The databases such as PubMed, Nature, Science Direct, Spring, Embase, The Cochrane Library and Web of Sciences were selected for articles search. The main search words were "Selective cesarean section", "Vaginal delivery", "Cesarean section", "Pelvic floor", and "Perineal Ultrasound". Random combinations of different search terms were used and input into each database for target literature retrieval. The publication time of the retrieved literature was set as 1 January 2010 to 1 August 2021. The search was conducted without language restriction.

\section{Literature selection and quality evaluation}

Based on the Cochrane system, the quality of the included articles was evaluated, and the articles were extracted separately by two reviewers, so as to exclude articles that did not meet the requirements or were of low quality. When the evaluation results were inconsistent, the two reviewers decided together whether to include the article in question through discussion, or a third reviewer was invited to arbitrate.

When the Cochrane Working Manual (https://training. cochrane.org/handbook) is used to evaluate the quality of the included literatures, comprehensive evaluation of the articles should be carried out in the following aspects. (I) Whether the study clearly explained the generation method of random sequence. (II) Whether there were hidden allocation problems in the study. (III) Whether there was a blind controlled study of participants and personnel in the article. (IV) Whether a blind method was used to evaluate the results. (V) Whether the data of evaluation results were complete. (VI) Whether the results were reported selectively. (VII) Other bias. Subsequently, the quality of the included literatures was evaluated jointly with Jadad scale. Finally, articles with a Jadad scale score greater than 3 were selected for inclusion in this meta-analysis.

\section{Extraction of literature information}

Data was extracted from the included articles by two literature reviewers, and the extracted information included the following: (I) author information; (II) year of publication; (III) grouping method; (IV) sample size; (V) delivery method; (VI) pelvic floor muscle strength; (VII) maximum urine flow; (VIII) posterior bladder angle; (IX) decreased bladder neck; (X) incidence of SUI; and (XI) incidence of pelvic floor organ prolapse.

\section{Statistical methods}

The software Excel 2016 (Microsoft Corp., Redmond, WA, USA) was used to sort out the data in the included literature, and the Cochrane Review Handbook and Jadad scale were used to evaluate the literature quality. The software Review Manager 5.3 (RevMan 5.3; The Nordic Cochrane Collaboration, Copenhagen Denmark, 2014) was used for meta-analysis of the included literature.

The heterogeneity analysis was as follows. The chi-square test was used to preliminarily test literature heterogeneity, and the significance level was set as $\alpha=0.05$, and $\mathrm{P}<0.05$. Then, $\mathrm{I}^{2}$ in RevMan5.3 was used for quantitative evaluation of heterogeneous results. Low heterogeneity existed when $\mathrm{I}^{2}<25 \%$. When $25 \%<\mathrm{I}^{2}<50 \%$, the literature had moderate heterogeneity. When $\mathrm{I}^{2}>50 \%$, the literature had substantial heterogeneity. Based on this, when $\mathrm{I}^{2}<50 \%$, the fixed effects model was used for meta-analysis. When $\mathrm{I}^{2}>50 \%$, the random-effects model was used for meta-analysis.

The statistical model of the combined effect was analyzed as follows. Dichotomous variables were described by relative risk (RR), odds ratio (OR), and risk difference (RD). Weighted mean difference (WMD) or standardized mean difference (SMD) were used to describe continuity variables. Sensitivity analysis was performed by excluding studies with the lowest quality scores. RevMan 5.3 was 


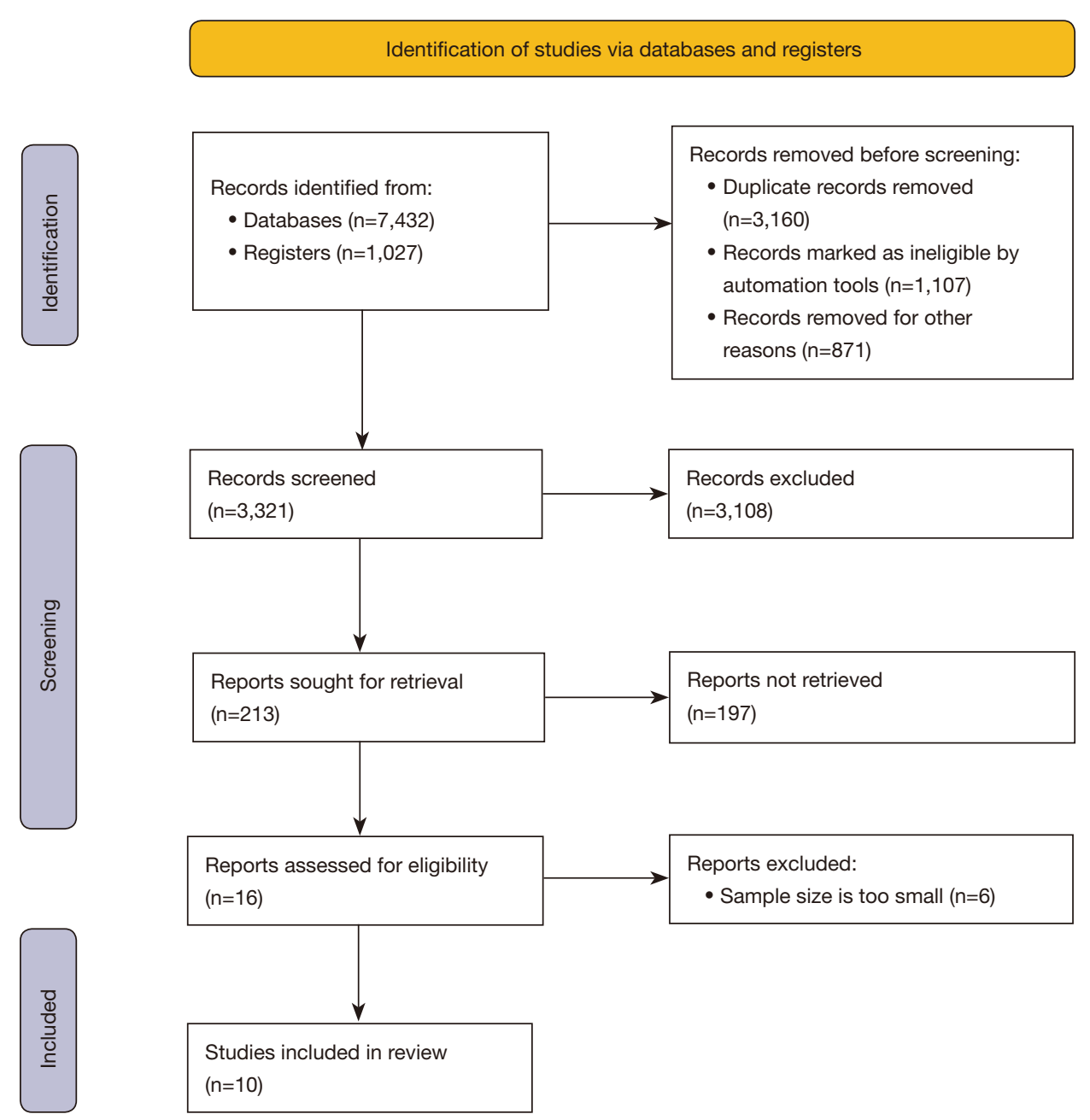

Figure 1 The basic process of literature retrieval.

used to output the forest map, and $\mathrm{Z}$ and $\mathrm{P}$ values in the results were extracted to judge the meta-analysis results. All effect sizes were expressed by $95 \%$ confidence interval (CI). When $\mathrm{P}<0.05$, the difference between groups was statistically significant.

\section{Results}

\section{Literature retrieval process}

After preliminary screening, 8,459 study titles or abstracts containing theme words "Selective Cesarean section", "Vaginal delivery", "Pelvic floor", and "Perineal Ultrasound" were obtained. A total of 3,321 studies were obtained after repeated and unqualified literatures had been eliminated. After a brief review of the title and abstract of each study, 3,108 articles inconsistent with the content of this study were removed, and 213 preliminary studies meeting the requirements were obtained. After review by 2 reviewers, 16 studies were screened according to the inclusion and exclusion criteria. After careful reading, articles with too small sample size were excluded, and a total of 10 studies were included for meta-analysis (10-19). The literature retrieval and screening process is illustrated in Figure 1.

\section{Basic information of the included literature}

The 10 articles included a total of 3,901 expectant mothers, including 1,188 cases of elective CSD and 2,713 cases of VD. The basic information of the included literature is illustrated in Table 1. 
Table 1 Basic information of the included literature

\begin{tabular}{|c|c|c|c|c|}
\hline First author & Year & Sample size & CSD sample size & VD sample size \\
\hline Batista (11) & 2011 & 61 & 30 & 31 \\
\hline Baud (12) & 2020 & 517 & 208 & 309 \\
\hline Caroci Ade (13) & 2010 & 110 & 37 & 73 \\
\hline Crane (15) & 2013 & 109 & 56 & 53 \\
\hline Gyhagen (16) & 2014 & 2,428 & 532 & 1,896 \\
\hline Hilde (17) & 2013 & 74 & 29 & 45 \\
\hline Hongliang (18) & 2021 & 156 & 78 & 78 \\
\hline
\end{tabular}

$\mathrm{CSD}$, cesarian section delivery; VD, vaginal delivery.



Figure 2 Bar charts of risk assessment of bias in included literature.

\section{Quality evaluation of the included literature}

First, the Cochrane Review Handbook was used for quality evaluation of the 10 articles included, and an evaluation chart was drawn for the overall evaluation of literature quality. The results are shown in Figures 2,3. The random sequence generation (selection bias), allocation concealment (selection bias), and blinding of participants and personal (performance bias) of the 10 papers included in the metaanalysis in this study were all classified as "low risk". Blinding of outcome assessment (detection bias) in 1 article was classified as "unclear risk", and the others were all "low risk". Incomplete outcome data (attrition bias) of 2 articles was classified as "unclear risk", 1 was "high risk", and the others were all "low risk". There were 3 articles involving selective reporting bias classified as "unbelievable risk", 1 was "high risk", and the rest were all "low risk". The other bias of the 10 articles were "unbelievable risk". Therefore, literature quality evaluations conducted by the Cochrane Review Handbook were all above grade B.

Subsequently, the Jadad scale was used to evaluate the quality of the included articles, and it was found that the Jadad scale scores of the included literatures were all greater than 3 points, so sensitivity analysis was not required.

\section{Meta-analysis of pelvic floor muscle strength of parturient women under different delivery modes}

The differences in postpartum pelvic floor muscle strength between the CSD group and the VD group were compared 


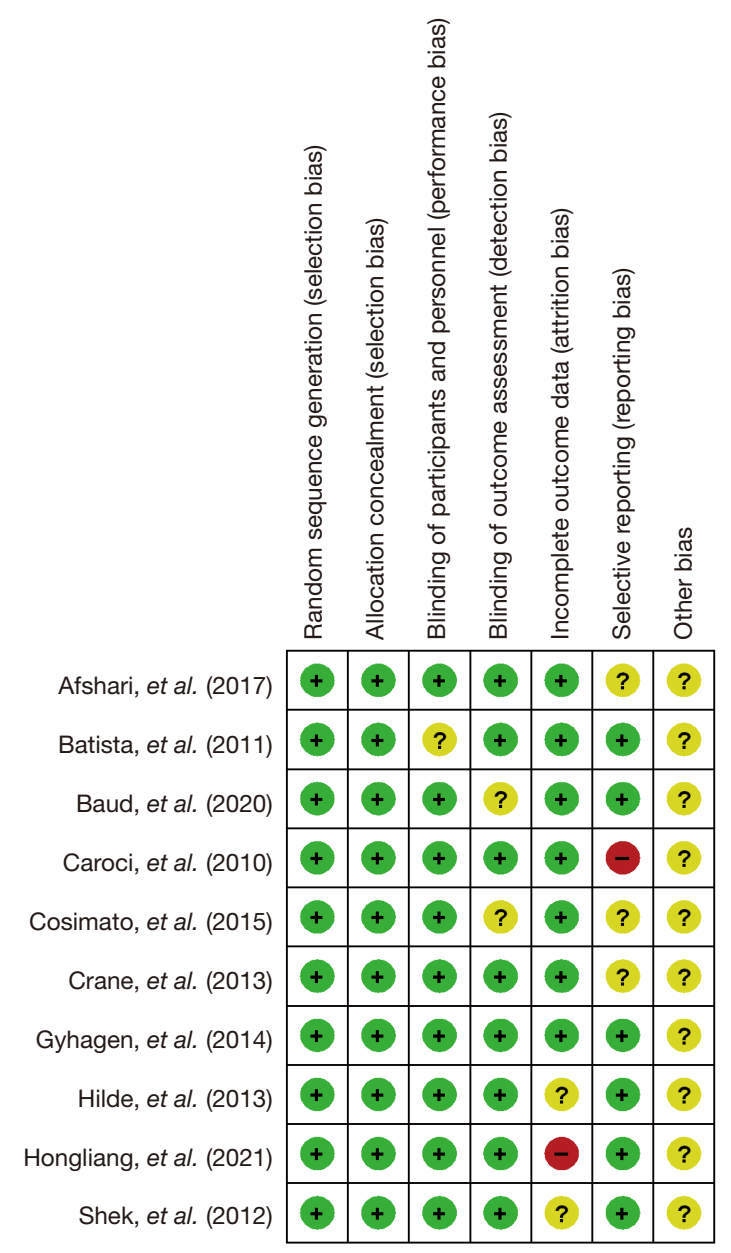

Figure 3 Summary of risk assessment of bias in the included literature.

and analyzed, as illustrated in Figure 4. After analysis of the heterogeneity of postpartum pelvic floor muscle strength between groups, the results showed that there was high heterogeneity in this index $\left(\mathrm{I}^{2}=91 \% ; \mathrm{P}<0.00001\right)$. Therefore, the random effects model was used for statistical analysis of combined effect values. Meta-analysis of the combined effect statistical model showed that the combined effect value of puerperal pelvic floor muscle strength in CSD group and VD group was [MD (95\% CI): $-12.51(-17.10$ to -7.91$)]$. The statistical test showed that $\mathrm{Z}=5.34, \mathrm{P}<0.00001$. In short, postpartum pelvic floor muscle strength in CSD group was dramatically higher than that in $\mathrm{VD}$ group $(\mathrm{P}<0.05)$.

\section{Meta-analysis of maximum urine flow of parturient women under different delivery modes}

The differences between the CSD group and VD group were compared and analyzed, and the results are shown in Figure 5. The heterogeneity of maximum postpartum urine flow between groups was analyzed, and the results showed high heterogeneity $\left(\mathrm{I}^{2}=91 \% ; \mathrm{P}<0.00001\right)$. Therefore, the random effects model was used for statistical analysis of combined effect values. Meta-analysis of the combined effect statistical model showed that the combined effect value of maximum postpartum urine flow in CSD group and VD group was [MD (95\% CI): -6.86 (-9.32 to -4.39)]. The statistical test was $Z=5.46, P<0.00001$. In short, the maximum postpartum urine flow in CSD group was dramatically lower than that in VD group $(\mathrm{P}<0.05)$.

\section{Meta-analysis of posterior bladder angle of parturient women in different delivery modes}

Perineal ultrasound was used to evaluate and compare the difference between the CSD group and VD group in postpartum posterior bladder angle, as illustrated in Figure 6. After analysis of the heterogeneity of postnatal posterior angle of the bladder between groups, the results showed that there was low heterogeneity in this index $\left(\mathrm{I}^{2}=0 \% ; \mathrm{P}=0.58\right)$. Therefore, a fixed effects model was used for statistical analysis of combined effect values. Metaanalysis of the combined effect statistical model showed that the combined effect value of postpartum posterior bladder angle in the CSD group and VD group was [MD (95\% CI): $-3.82(-4.54$ to -3.11$)]$. The statistical test was $Z=10.46$, $\mathrm{P}<0.00001$. In short, postpartum posterior bladder angle in the CSD group was dramatically smaller than that in VD group $(\mathrm{P}<0.05)$.

\section{Meta-analysis of maternal bladder neck decline under different delivery modes}

The difference of postpartum bladder neck decline between CSD group and VD group was evaluated and compared by perineal ultrasound, as illustrated in Figure 7. The heterogeneity of postpartum bladder neck decline between groups was analyzed, and the results showed that there was low heterogeneity in this index $\left(\mathrm{I}^{2}=0 \% ; \mathrm{P}=0.70\right)$. Therefore, a fixed effects model was used for statistical analysis of 


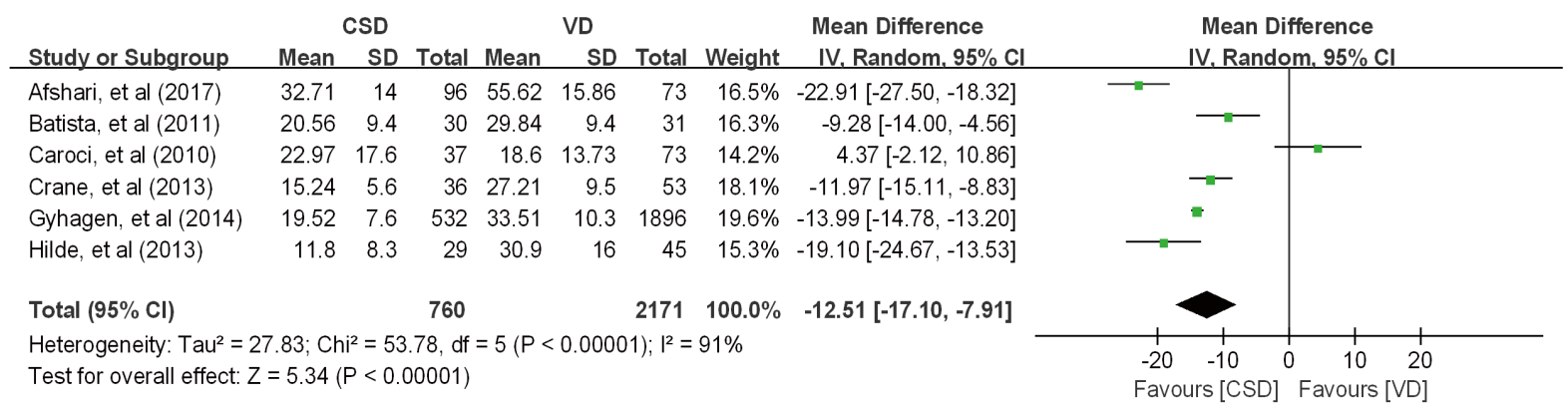

Figure 4 Forest plot of pelvic floor muscle strength comparison between CSD group and VD group after delivery. CSD, cesarian section delivery; VD, vaginal delivery; SD, standard deviation; CI, confidence interval.

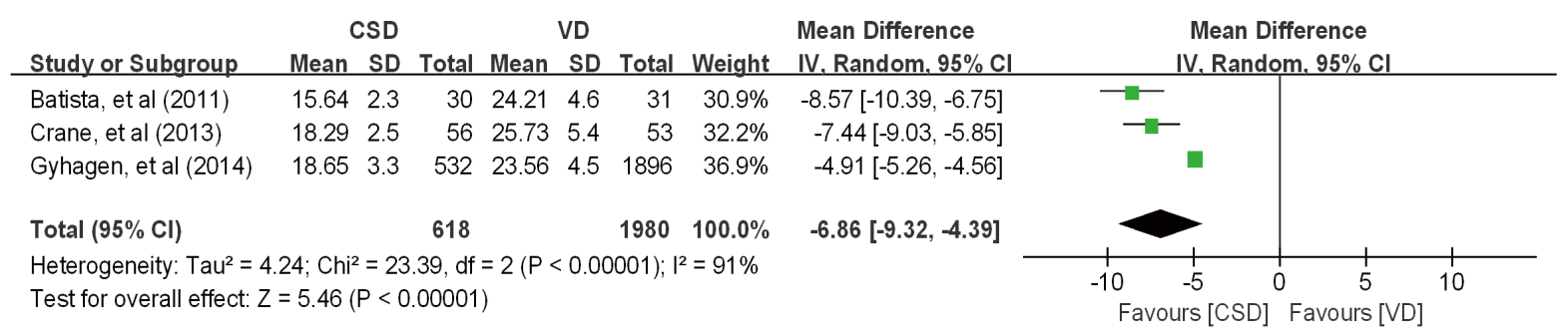

Figure 5 Forest plot of comparison of maximum urine flow after delivery between CSD group and VD group. CSD, cesarian section delivery; VD, vaginal delivery; SD, standard deviation; CI, confidence interval.

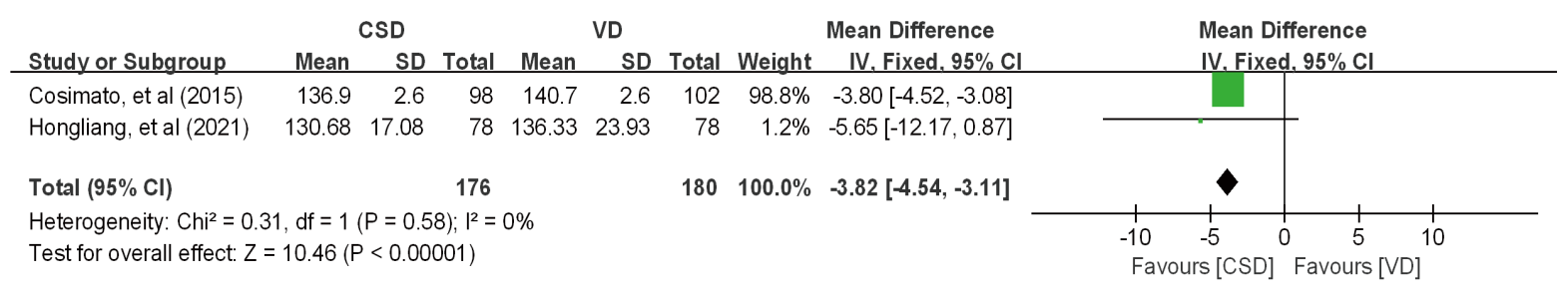

Figure 6 Forest plot of comparison of posterior bladder angle between CSD group and VD group after delivery. CSD, cesarian section delivery; VD, vaginal delivery; SD, standard deviation; CI, confidence interval.

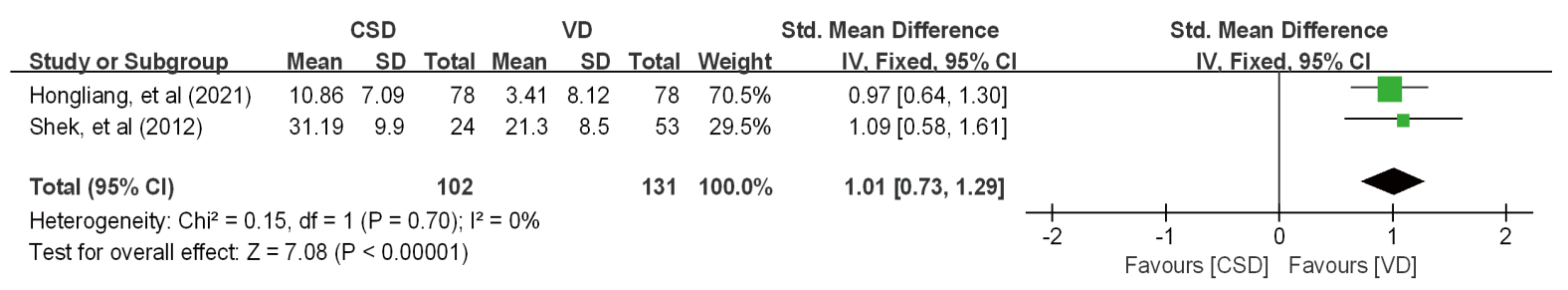

Figure 7 Forest plot comparing the decline of bladder neck after delivery between CSD group and VD group. CSD, cesarian section delivery; VD, vaginal delivery; SD, standard deviation; CI, confidence interval. 


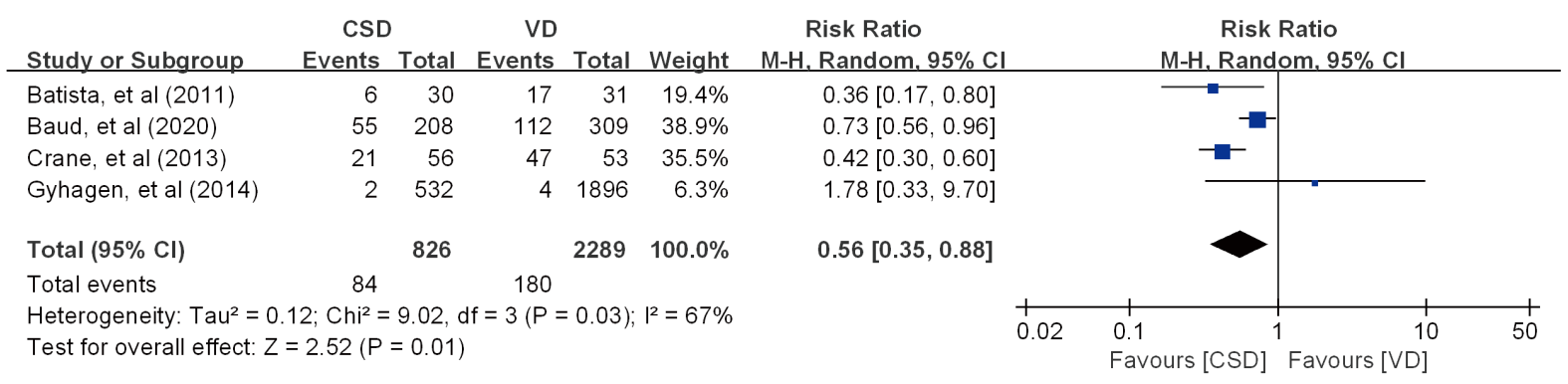

Figure 8 Forest plot comparing the incidence of SUI after delivery between CSD group and VD group. SUI, stress urinary incontinence; CSD, cesarian section delivery; VD, vaginal delivery; CI, confidence interval.

\begin{tabular}{|c|c|c|c|c|c|c|c|c|c|c|}
\hline Study or Subgroup & $\begin{array}{l}\text { CSD } \\
\text { Events }\end{array}$ & Total & $\begin{array}{r}\text { VD } \\
\text { Events }\end{array}$ & Total & Weight & $\begin{array}{l}\text { Odds Ratio } \\
\text { M-H, Random, } 95 \% \mathrm{Cl}\end{array}$ & & $\begin{array}{r}\text { Odds } \\
\mathrm{M}-\mathrm{H}, \text { Rand }\end{array}$ & $\begin{array}{l}\text { Ratio } \\
\text { lom, } 95 \% \mathrm{Cl}\end{array}$ & \\
\hline Batista, et al (2011) & 7 & 30 & 21 & 31 & $24.5 \%$ & $0.14[0.05,0.45]$ & & + & & \\
\hline Baud, et al (2020) & 138 & 208 & 237 & 309 & $31.4 \%$ & $0.60[0.41,0.88]$ & & - & & \\
\hline Crane, et al (2013) & 28 & 56 & 49 & 53 & $24.3 \%$ & $0.08[0.03,0.26]$ & & & & \\
\hline Gyhagen, et al (2014) & 2 & 532 & 7 & 1896 & $19.8 \%$ & $1.02[0.21,4.92]$ & & & & \\
\hline Total $(95 \% \mathrm{Cl})$ & & 826 & & 2289 & $100.0 \%$ & $0.29[0.09,0.89]$ & & & & \\
\hline Total events & 175 & & 314 & & & & & & & \\
\hline $\begin{array}{l}\text { Heterogeneity: } \mathrm{Tau}^{2}= \\
\text { Test for overall effect: }\end{array}$ & $\begin{array}{l}\text { OO; } \mathrm{Chi}^{2}= \\
=2.17(\mathrm{P}\end{array}$ & $\begin{array}{r}15.59 \\
=0.03)\end{array}$ & $d f=3(P$ & $=0.00$ & 1); $\left.\right|^{2}=81 \%$ & & 0.01 & $\begin{array}{l}0.1 \\
\text { Favours [CSD] }\end{array}$ & $\begin{array}{lr}1 & 10 \\
\text { Favours [VD] }\end{array}$ & 100 \\
\hline
\end{tabular}

Figure 9 Forest plot comparing the incidence of pelvic floor organ prolapse after delivery between CSD group and VD group. CSD, cesarian section delivery; VD, vaginal delivery; CI, confidence interval.

combined effect values. The combined effect of CSD group and VD group was [SMD (95\% CI): 1.01 (0.73 to 1.29)]. The statistical test was $Z=7.08, P<0.00001$. In short, postpartum bladder neck decline in the CSD group was dramatically greater than that in the VD group $(\mathrm{P}<0.05)$.

\section{Meta-analysis of the incidence of SUI in women with different delivery modes}

The difference in the incidence of postpartum SUI between the CSD group and the VD group was compared and analyzed, as illustrated in Figure 8. The heterogeneity of the incidence of postpartum SUI between groups was analyzed, and the results showed that there was low heterogeneity in this index $\left(\mathrm{I}^{2}=67 \% ; \mathrm{P}=0.03\right)$. Therefore, a random effects model was used for statistical analysis of combined effect values. Meta-analysis of the combined effect statistical model showed that the combined effect value of the incidence of postpartum SUI in the CSD group and VD group was [RR (95\% CI): $0.56(0.35$ to 0.88$)$ ]. The statistical test was $\mathrm{Z}=2.52, \mathrm{P}=0.01$. In short, the incidence of postpartum SUI in CSD group was dramatically lower than that in the VD group $(\mathrm{P}<0.05)$.

\section{Meta-analysis of the incidence of pelvic floor organ prolapses under different delivery modes}

The difference in the incidence of postpartum pelvic floor organ prolapses between the CSD group and the VD group was compared and analyzed, as illustrated in Figure 9. The heterogeneity of the incidence of postpartum pelvic floor organ prolapse between groups was analyzed, and the results showed that there was low heterogeneity in this indicator $\left(\mathrm{I}^{2}=81 \% ; \mathrm{P}=0.001\right)$. Therefore, a random effects model was used for statistical analysis of combined effect values. Metaanalysis of the combined effect statistical model showed that the combined effect value of the incidence of postpartum pelvic floor organ prolapse in the CSD group and VD group was [OR (95\% CI): 0.29 (0.09 to 0.89)]. Statistical test was $\mathrm{Z}=2.17, \mathrm{P}=0.03$. In short, the incidence of puerperal pelvic floor organ prolapse in CSD group was dramatically lower than that in $\mathrm{VD}$ group $(\mathrm{P}<0.05)$. 


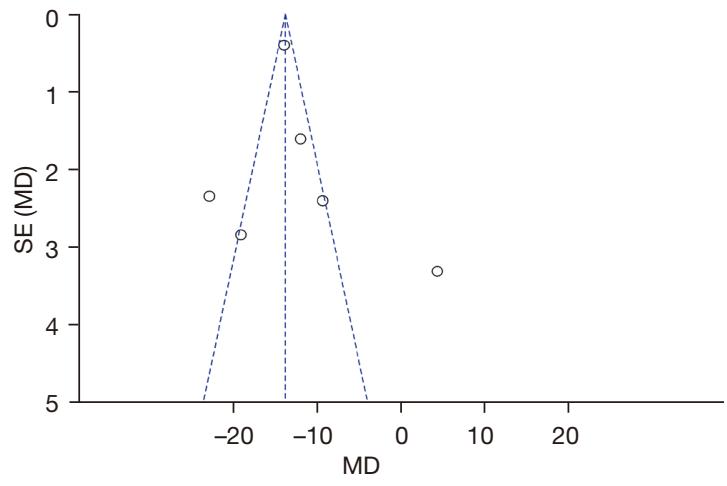

Figure 10 Inverted funnel plot of pelvic floor muscle strength evaluation after delivery in CSD group and VD group. CSD, cesarian section delivery; VD, vaginal delivery; SE, standard error; MD, mean difference.

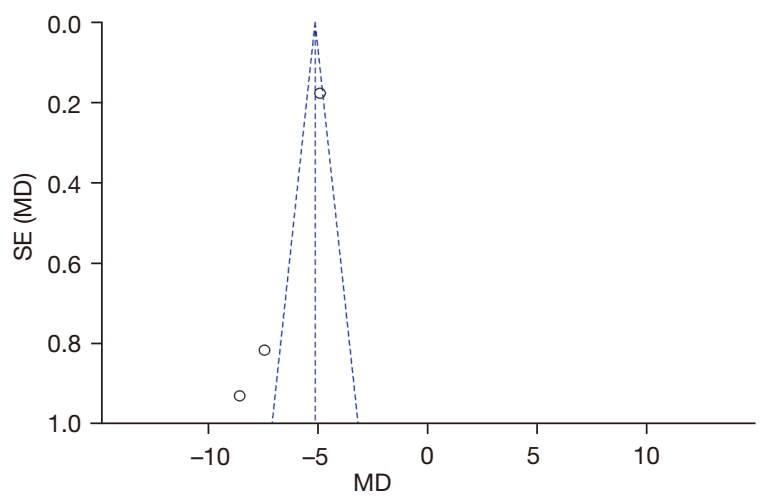

Figure 11 Inverted funnel plot of the evaluation of maximum urine flow after delivery in the CSD group and VD group. CSD, cesarian section delivery; VD, vaginal delivery; SE, standard error; MD, mean difference.

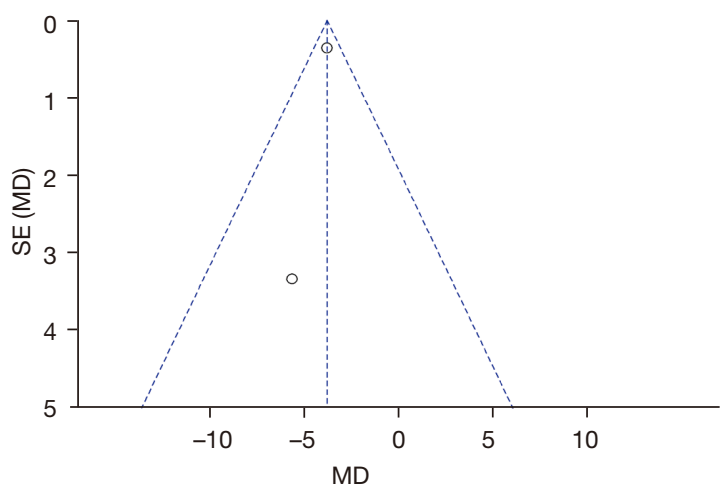

Figure 12 Inverted funnel plot of posterior bladder angle after delivery in CSD group and VD group. CSD, cesarian section delivery; $\mathrm{VD}$, vaginal delivery; SE, standard error; $\mathrm{MD}$, mean difference.

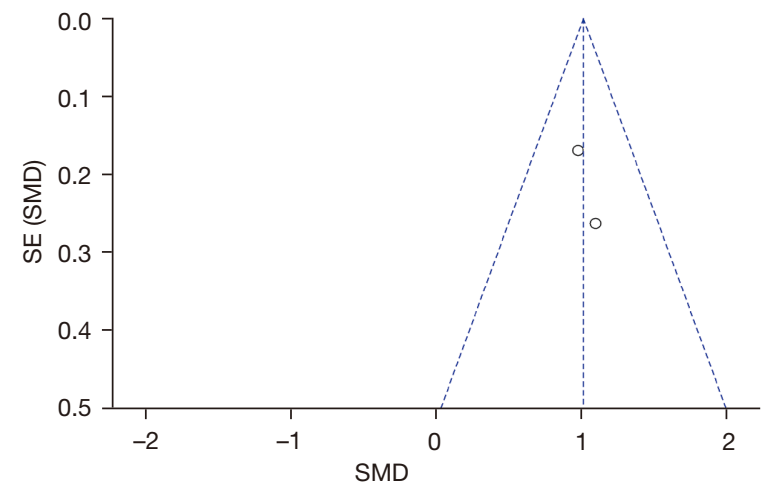

Figure 13 Inverted funnel plot of bladder neck decline evaluation after delivery in CSD group and VD group. CSD, cesarian section delivery; VD, vaginal delivery; SE, standard error; SMD, standardized mean difference.



Figure 14 Inverted funnel plot of post-delivery SUI evaluation in CSD group and VD group. SUI, stress urinary incontinence; CSD, cesarian section delivery; VD, vaginal delivery; SE, standard error; $\mathrm{RR}$, relative risk.

\section{Analysis of literature publication bias}

An inverted funnel plot was drawn to analyze the publication bias of each maternal inclusion outcome index in the CSD group and VD group, as illustrated in Figures 10-15. The inverted funnel plots of all the included outcome indicators were symmetrical, and almost all of the included studies fell within the inverted funnel plots. Only some studies on pelvic floor muscle strength and maximum urine flow did not fall into the inverted funnel plot. On the whole, the inclusion of each index was almost close to the central axis. It indicated that the publication bias of all the indexes used for analysis in the included literature was low and met the requirements. 


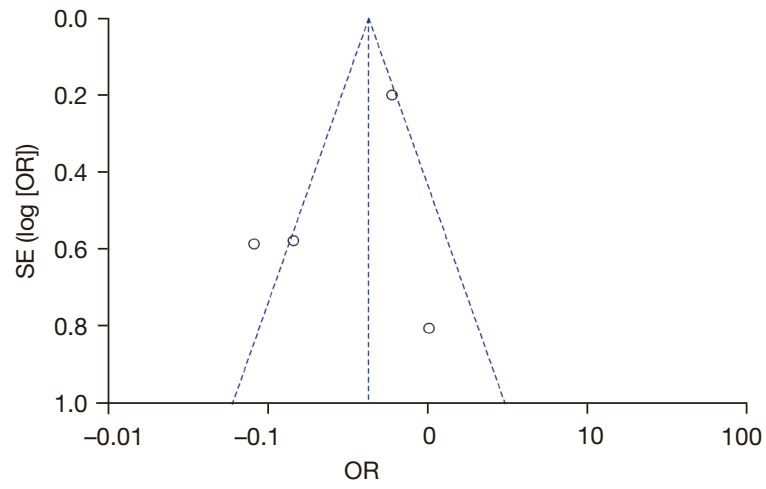

Figure 15 Inverted funnel plot of evaluation of the incidence of pelvic floor organ prolapses after delivery in CSD group and VD group. CSD, cesarian section delivery; VD, vaginal delivery; SE, standard error; OR, odds ratio.

\section{Discussion}

In non-gestational women, the uterus often presents a forward-leaning and forward-flexion position, with the combined weight of the pelvic organs and the supporting force of the pelvic floor tissues toward the sacral caudal position (20). As pregnancy progresses, the weight and volume of the uterus increase, and the position of the uterus gradually changes to a vertical position, requiring greater support from pelvic floor tissue (21). Female pelvic floor dysfunction is a disease caused by congenital pelvic floor tissue weakness or degeneration, or later pelvic floor muscles, fascia, ligament, and other supporting structures to maintain organ balance loss or dysfunction (22). In recent years, SUI and pelvic floor dysfunction have gradually become the common types of pelvic floor dysfunction in women (23). Studies have shown that there are many factors causing pelvic floor dysfunction, mainly age, weight, menopause, pregnancy and childbirth, as well as diabetes. Pregnancy and childbirth are the most important independent risk factors for female pelvic floor dysfunction $(24,25)$. During pregnancy and childbirth, the pelvic floor structure may undergo physiological and anatomical changes that may damage the structure and function of the pelvic floor to varying degrees (26).

In recent years, with the gradual development of economic level and living standard, the clinical cesarean section rate, especially the rate of selective cesarean section, has shown a trend of gradual increase (27). Studies have found that increased abdominal pressure during delivery, $V D$, lateral resection of the perineum, and excessive newborn weight will cause different degrees of damage to the perineal nerve, levator ani muscle, fascia, and other pelvic support structures, which then directly or indirectly contribute to the occurrence of pelvic floor dysfunction diseases (28). During VD, the fetal head descends, which produces huge mechanical compression and stretch on the pelvic floor muscles and pudendal nerve. Some researchers found that the pudendal nerve conduction time of VD was significantly longer than that of elective cesarean section, reflecting the nerve-damaging effect of VD (29). The direct damage and ischemia-reperfusion injury of the pelvic floor support tissue during VD can weaken, degenerate, or even break the links of collagen fibers and elastic fibers in the pelvic floor, resulting in weakened pelvic organ support and increased incidence of pelvic floor dysfunction disorders (30). Elective cesarean section can avoid the extreme compression and pulling of the pelvic floor supporting tissue by the fetal head during the vaginal trial and the second stage of labor, which has a temporary protective effect on the pelvic floor function (31). However, while the cesarean section operation causes iatrogenic trauma to the uterus, it will also cause a certain degree of damage to the muscles and fascia of the pelvic floor, destroying the normal anatomical structure of the human body. It also increases the incidence of postoperative complications such as incision infection, scar pregnancy, pelvic adhesions, endometriosis, and chronic pelvic pain $(32,33)$. At present, trans-perineal pelvic floor ultrasound has obvious advantages in clinical diagnosis and efficacy evaluation of female pelvic floor dysfunction, so it has become the preferred method to evaluate the pelvic floor structure and function of patients (34).

Therefore, this work explored the effects of selective CSD and VD on puerperal pelvic floor function of primiparas based on meta-analysis, and evaluated by transperineal pelvic floor ultrasound. The results showed that the pelvic floor muscle strength and bladder neck decline of women in selective CSD were dramatically greater than those in the VD group. The maximal urine flow, posterior bladder angle, SUI rate, and pelvic floor organ prolapse rate of women in elective CSD group were dramatically lower than those in the VD group. Studies have indicated that the increased posterior angle of the urethra and bladder increases posterior urethral activity or instability, thus increasing the incidence of SUI $(35,36)$. This study indicated that selective CSD can reduce the incidence of women's pelvic floor dysfunction by reducing the degree of maternal pelvic floor dysfunction. 
However, due to the limited number of included studies, there are relatively few clinical studies using trans-perineal pelvic floor ultrasound to evaluate the pelvic floor function of primiparas with different delivery modes. Therefore, only 2 studies were included which analyzed the posterior angle of the bladder and the decline of the bladder neck. To verify the result that selective CSD can reduce the incidence of female pelvic floor dysfunction, further exploration in combination with clinical practical studies should be conducted in the future.

\section{Conclusions}

In this study, meta-analysis was used to explore the difference in pelvic floor function of primiparas after selective CSD and VD. The results showed that selective CSD could reduce the incidence of SUI and pelvic floor organ prolapse after pregnancy and delivery by reducing the damage degree of pelvic floor muscle and other supporting structures, but could not completely avoid it. The results provide medical evidence for the early post-parturient pelvic floor function recovery training in clinical practice.

\section{Acknowledgments}

Funding: None.

\section{Footnote}

Reporting Checklist: The authors have completed the MOOSE reporting checklist. Available at https://apm. amegroups.com/article/view/10.21037/apm-22-46/rc

Conflicts of Interest: All authors have completed the ICMJE uniform disclosure form (available at https://apm. amegroups.com/article/view/10.21037/apm-22-46/coif). The authors have no conflicts of interest to declare.

Ethical Statement: The authors are accountable for all aspects of the work in ensuring that questions related to the accuracy or integrity of any part of the work are appropriately investigated and resolved.

Open Access Statement: This is an Open Access article distributed in accordance with the Creative Commons Attribution-NonCommercial-NoDerivs 4.0 International License (CC BY-NC-ND 4.0), which permits the noncommercial replication and distribution of the article with the strict proviso that no changes or edits are made and the original work is properly cited (including links to both the formal publication through the relevant DOI and the license). See: https://creativecommons.org/licenses/by-nc-nd/4.0/.

\section{References}

1. Betschart C, Singer A, Scheiner D. Female pelvic floor: anatomy and normal function. Ther Umsch 2019;73:529-34.

2. Memon HU, Blomquist JL, Dietz HP, et al. Comparison of levator ani muscle avulsion injury after forceps-assisted and vacuum-assisted vaginal childbirth. Obstet Gynecol 2015;125:1080-7.

3. Blomquist JL, Carroll M, Muñoz A, et al. Pelvic floor muscle strength and the incidence of pelvic floor disorders after vaginal and cesarean delivery. Am J Obstet Gynecol 2020;222:62.e1-8.

4. Wallace SL, Miller LD, Mishra K. Pelvic floor physical therapy in the treatment of pelvic floor dysfunction in women. Curr Opin Obstet Gynecol 2019;31:485-93.

5. Van Geelen H, Ostergard D, Sand P. A review of the impact of pregnancy and childbirth on pelvic floor function as assessed by objective measurement techniques. Int Urogynecol J 2018;29:327-38.

6. Ghafar MA, Chesson RR, Velasco C, et al. Size of urogenital hiatus as a potential risk factor for emptying disorders after pelvic prolapse repair. J Urol 2013;190:603-7.

7. Angelo PH, Varella LRD, de Oliveira MCE, et al. A manometry classification to assess pelvic floor muscle function in women. PLoS One 2017;12:e0187045.

8. Navarro Brazález B, Sánchez Sánchez B, Prieto Gómez $\mathrm{V}$, et al. Pelvic floor and abdominal muscle responses during hypopressive exercises in women with pelvic floor dysfunction. Neurourol Urodyn 2020;39:793-803.

9. Rørtveit G, Hannestad YS. Association between mode of delivery and pelvic floor dysfunction. Tidsskr Nor Laegeforen 2014;134:1848-52.

10. Afshari P, Dabagh F, Iravani M, et al. Comparison of pelvic floor muscle strength in nulliparous women and those with normal vaginal delivery and cesarean section. Int Urogynecol J 2017;28:1171-5.

11. Batista EM, Conde DM, Do Amaral WN, et al. Comparison of pelvic floor muscle strength between women undergoing vaginal delivery, cesarean section, and nulliparae using a perineometer and digital palpation. Gynecol Endocrinol 2011;27:910-4. 
12. Baud D, Sichitiu J, Lombardi V, et al. Comparison of pelvic floor dysfunction 6 years after uncomplicated vaginal versus elective cesarean deliveries: a cross-sectional study. Sci Rep 2020;10:21509.

13. Caroci AS, Riesco ML, Sousa Wda S, et al. Analysis of pelvic floor musculature function during pregnancy and postpartum: a cohort study: (a prospective cohort study to assess the PFMS by perineometry and digital vaginal palpation during pregnancy and following vaginal or caesarean childbirth). J Clin Nurs 2010;19:2424-33.

14. Cosimato C, Cipullo LM, Troisi J, et al. Ultrasonographic evaluation of urethrovesical junction mobility: correlation with type of delivery and stress urinary incontinence. Int Urogynecol J 2015;26:1495-502.

15. Crane AK, Geller EJ, Bane H, et al. Evaluation of pelvic floor symptoms and sexual function in primiparous women who underwent operative vaginal delivery versus cesarean delivery for second-stage arrest. Female Pelvic Med Reconstr Surg 2013;19:13-6.

16. Gyhagen M, Bullarbo M, Nielsen TF, et al. Faecal incontinence 20 years after one birth: a comparison between vaginal delivery and caesarean section. Int Urogynecol J 2014;25:1411-8.

17. Hilde G, Stær-Jensen J, Siafarikas F, et al. Impact of childbirth and mode of delivery on vaginal resting pressure and on pelvic floor muscle strength and endurance. Am J Obstet Gynecol 2013;208:50.e1-7.

18. Hongliang Y, Pengfei L, Cuiping J, et al. Pelvic floor function and morphological abnormalities in primiparas with postpartum symptomatic stress urinary incontinence based on the type of delivery: a 1:1 matched case-control study. Int Urogynecol J 2021. [Epub ahead of print]. doi: 10.1007/s00192-021-04816-9.

19. Shek KL, Chantarasorn V, Langer S, et al. Does levator trauma 'heal'? Ultrasound Obstet Gynecol 2012;40:570-5.

20. Eickmeyer SM. Anatomy and Physiology of the Pelvic Floor. Phys Med Rehabil Clin N Am 2017;28:455-60.

21. Schreiner L, Crivelatti I, de Oliveira JM, et al. Systematic review of pelvic floor interventions during pregnancy. Int J Gynaecol Obstet 2018;143:10-8.

22. Grigoriadis T, Athanasiou S, Rizk D. Female pelvic floor dysfunction questionnaires: the modern Tower of Babel? Int Urogynecol J 2020;31:1059-61.

23. Kam HA, Yagel S, Eisenberg VH. Ultrasonography in Pelvic Floor Dysfunction. Obstet Gynecol Clin North Am 2019;46:715-32.

24. Cameron B, Sabourin J, Sanaee MS, et al. Pelvic floor hypertonicity in women with pelvic floor disorders: A case control and risk prediction study. Neurourol Urodyn 2019;38:696-702.

25. Tähtinen RM, Cartwright R, Tsui JF, et al. Longterm Impact of Mode of Delivery on Stress Urinary Incontinence and Urgency Urinary Incontinence: A Systematic Review and Meta-analysis. Eur Urol 2016;70:148-58.

26. Routzong MR, Rostaminia G, Moalli PA, et al. Pelvic floor shape variations during pregnancy and after vaginal delivery. Comput Methods Programs Biomed 2020;194:105516.

27. Olieman RM, Siemonsma F, Bartens MA, et al. The effect of an elective cesarean section on maternal request on peripartum anxiety and depression in women with childbirth fear: a systematic review. BMC Pregnancy Childbirth 2017;17:195.

28. Bozkurt M, Yumru AE, Şahin L. Pelvic floor dysfunction, and effects of pregnancy and mode of delivery on pelvic floor. Taiwan J Obstet Gynecol 2014;53:452-8.

29. Chandra A, Kumar S, Singh P, et al. Endoscopic ultrasound-guided anal sphincteroplasty for fecal incontinence in women: A pilot study. Indian J Gastroenterol 2019;38:534-41.

30. Hutton EK, Hannah ME, Willan AR, et al. Urinary stress incontinence and other maternal outcomes 2 years after caesarean or vaginal birth for twin pregnancy: a multicentre randomised trial. BJOG 2018;125:1682-90.

31. Barbosa AM, Marini G, Piculo F, et al. Prevalence of urinary incontinence and pelvic floor muscle dysfunction in primiparae two years after cesarean section: crosssectional study. Sao Paulo Med J 2013;131:95-9.

32. Rosa F, Perugin G, Schettini D, et al. Imaging findings of cesarean delivery complications: cesarean scar disease and much more. Insights Imaging 2019;10:98.

33. Tekelioğlu M, Karataş S, Güralp O, et al. Incomplete healing of the uterine incision after elective second cesarean section. J Matern Fetal Neonatal Med 2021;34:943-7.

34. Leombroni M, Buca D, Liberati M, et al. Post-partum pelvic floor dysfunction assessed on $3 \mathrm{D}$ rotational ultrasound: a prospective study on women with first- and second-degree perineal tears and episiotomy. J Matern Fetal Neonatal Med 2021;34:445-55.

35. Kawakami S, Yamada T, Watanabe T, et al. Significance of transrectal ultrasonography in surgery for stress urinary incontinence and cystocele. Assessment of the bladder 
neck suspension by measuring posterior urethrovesical angle and angle of inclination of the upper urethra. Nihon Hinyokika Gakkai Zasshi 1994;85:1066-71.

36. Li YQ, Geng J, Tan C, et al. Diagnosis and classification of female stress urinary incontinence by transperineal

Cite this article as: Chen $\mathrm{Y}$, Geng $\mathrm{X}$, Zhou H, Wang W, Liang Y, Zhang C, Wang L. Systematic review and metaanalysis of evaluation of selective cesarean section in postpartum pelvic floor function recovery under perineal ultrasound. Ann Palliat Med 2022;11(2):730-742. doi: 10.21037/apm-22-46 two-dimensional ultrasound. Technol Health Care 2017;25:859-66.

(English Language Editor: J. Jones) 